\title{
Changes in epizoic crustacean infestations during cetacean die-offs: the mass mortality of Mediterranean striped dolphins Stenella coeruleoalba revisited
}

\author{
F. J. Aznar*, D. Perdiguero, A. Pérez del Olmo, A. Repullés, C. Agustí, J. A. Raga \\ Marine Zoology Unit, Cavanilles Institute of Biodiversity and Evolutionary Biology, University of Valencia, PO Box 22085, \\ 46071 Valencia, Spain
}

\begin{abstract}
In the summer and autumn of 1990, a cetacean morbillivirus caused a massive epizootic mortality of striped dolphins Stenella coeruleoalba in the western Mediterranean. Previous circumstantial evidence suggested that the disease could also have increased host susceptibility to infestations with epizoic crustaceans. In this study we provide strong evidence supporting this hypothesis. We examined striped dolphins stranded along the Mediterranean central coast of Spain from 1981 to $2004(n=136)$, and recorded data on prevalence, intensity of infestation, size and reproductive status of 2 sessile crustacean species specific to cetaceans, the phoront cirriped Xenobalanus globicipitis and the mesoparasitic copepod Pennella balaenopterae. Compared with the pre-epizootic $(\mathrm{n}=12)$ and post-epizootic $(\mathrm{n}=62)$ dolphin samples, the following changes were noted in the dolphins stranded during the epizootic $(\mathrm{n}=62)$ : (1) the prevalence of both $X$. globicipitis and $P$. balaenopterae increased; (2) the intensity of $X$. globicipitis and $P$. balaenopterae infestations did not increase; indeed, it was even slightly lower than in the other periods, as was their degree of aggregation; (3) individuals of both species were smaller, and a higher proportion were non-gravid; (4) the 2 species tended to co-occur in the same dolphins, but their numbers did not co-vary. These patterns strongly suggest that, during the epizootic, there was a short-term increase in the probability of infestation of these 2 species because of the sudden rise in the population of susceptible hosts; the growth of the new recruits was limited by the early death of dolphins. The high susceptibility was likely related to the immunosuppressive effects of viral infection and the abnormally heavy loads of polychlorinated biphenyls found in sick dolphins; the level of inbreeding was also higher in dolphins from the 'epizootic' sample. Epizoic crustaceans could be suitable indicators of health in cetacean populations.
\end{abstract}

KEY WORDS: Cetacean - Morbillivirus - Epidemics - Mass mortality · Epibiont · Parasite · Susceptibility

\section{INTRODUCTION}

At the beginning of the last decade, a cetacean morbillivirus (CeMV) caused a massive epizootic mortality of striped dolphins Stenella coeruleoalba in the Mediterranean (Aguilar \& Raga 1993, Van Bressem et al. 1999). The outbreak first affected dolphins from the western region in summer 1990, when a high number of sick animals died shortly after being washed ashore. The high stranding rate persisted until the autumn and returned to normal rates the fol- lowing winter (Aguilar \& Raga 1993). Similar outbursts of epidemic mortality were subsequently recorded in the central and eastern Mediterranean regions during 1991 and 1992 (Di Guardo et al. 2005 and references therein). The total death toll could not be estimated precisely but mortality might have been substantial, in the order of several thousand animals (Aguilar \& Raga 1993, Forcada et al. 1994).

Morbilliviruses are well-known for their strong immunosuppressive effects (von Messling et al. 2003 and references therein). In cetaceans, the CeMV dis- 
ease provokes immunological depression that leads to secondary opportunistic infections, or activation of latent infections, of a variety of bacteria, fungi and protozoons (Domingo et al. 1992, Duignan et al. 1996). One of the most prominent clinical signs of the striped dolphins affected by the CeMV was the occurrence of apparently abnormal burdens of some epizoites (Aznar et al. 1994). In particular, a phoront barnacle specific to cetaceans, Xenobalanus globicipitis, was more frequently found during the epizootic period than in previous years. Also, many individuals were young, suggesting recent infestation events. We speculated that these patterns might have resulted from an increase of host susceptibility due to the CeMV disease (Aznar et al. 1994). However, the evidence at that time was circumstantial because we lacked sufficient pre- and post-epizootic data for comparison.

In this paper we revisit this hypothesis from a broader perspective. We have accumulated data during the last $24 \mathrm{yr}$, not only from Xenobalanus globicipitis, but also from a sessile parasitic copepod specific to cetaceans, Pennella balaenopterae. Each species thus provides an independent source of evidence to test the hypothesis. In particular, we compare infestation parameters and age of recruitment of both crustacean species in dolphins stranded before, during and after the outbreak. If the population of susceptible hosts had suddenly increased during the epidemic, dolphins should harbor higher burdens of both crustacean species, mainly of recent recruits (Aznar et al. 1994). The analysis simply assumes that the 'epizootic' sample contains a higher proportion of susceptible hosts than the 'non-epizootic' samples, whose individuals died from a variety of causes. The increase of host susceptibility during the epizootic could also be indicated by a significant positive association between the crustacean species, since each species has a different life style, i.e. phoront vs mesoparasitic (Holmstad \& Skorping 1998).

\section{MATERIALS AND METHODS}

Samples. Based on the pattern of strandings and the clinical signs and pathological analyses of dolphins, we considered that the epizootic extended from June to December 1990. To minimize the potential confounding effect of season in our comparisons, we selected dolphins from the same months in the other years. Therefore, 3 samples were defined: pre-epizootic (Pre-E) (June-December, 1981-1989) ( $\mathrm{n}=12$ ), epizootic (E) (June-December, 1990) ( $\mathrm{n}=62)$, and postepizootic (Post-E) (June-December, 1991-2004) ( $\mathrm{n}=$ 62). The analysis was restricted to dolphins whose skin was intact. The proportion of stranded dolphins with intact skin did not significantly differ between the 3 periods (Chi-Square test, exact $\mathrm{p}=0.26$ ).

Dolphins were found stranded along the Mediterranean coast of Spain $(556 \mathrm{~km}$ of coastline, from $40^{\circ} 31.5^{\prime} \mathrm{N}, 0^{\circ} 31.0^{\prime} \mathrm{E}$, to $\left.37^{\circ} 50.7^{\prime} \mathrm{N}, 1^{\circ} 37.5^{\prime} \mathrm{W}\right)$. Stranding events always involved solitary animals and their monthly distribution excluding the epizootic period did not depart from a Poisson distribution (Chi-Square test, Monte Carlo $\mathrm{p}=0.103$ ). The number of stranded animals increased over the years (Spearman correlation, $p$ $<0.0001$ ), but this phenomenon was common to other cetacean species (F. J. Aznar unpubl. data) and seems clearly attributable to the improvement of the stranding network (see also López et al. 2002).

Dolphins were sexed and measured to the nearest $0.5 \mathrm{~cm}$, then carefully examined for epizoic crustaceans. The presence of Xenobalanus globicipitis and Pennella balaenopterae was recorded from all hosts, but other data could not always be obtained because of difficult sampling conditions. The numbers of X. globicipitis and $P$. balaenopterae were counted in all but 3 dolphins ( 2 from the E sample and 1 from the Post-E sample). Individuals of $X$. globicipitis and P. balaenopterae were collected from 51 and 16 dolphins, respectively, representing $93 \%$ and $47 \%$ of the total number of dolphins infected with each species. Specimens were taken together with the surrounding host tissue and preserved in $70 \%$ ethanol. This material is deposited at the parasite collection of our laboratory. Identification of $P$. balaenopterae was based on descriptions by Abaunza et al. (2001), using 7 complete specimens.

After collecting the crustacean specimens, dolphins were generally necropsied. However, with the exception of individuals from the epizootic period, for which specific pathologic analyses were carried out (see Aznar et al. 1994), the cause of death was difficult to determine.

Estimation of relative age of Xenobalanus globicipitis and Pennella balaenopterae. Size was considered a reasonable proxy of relative age in X. globicipitis and $P$. balaenopterae since we were to compare individuals from the same host species, area and seasonal period. Crowding effects on size were not likely to confound comparisons because in both species, the mean number of individuals per dolphin did not differ between samples (see 'Results'). We estimated the relative age of $X$. globicipitis using the maximum diameter of the basal shell. The shell was the only structure that remained intact in many specimens, and maximum shell diameter shows a strong linear relationship with pseudocapitulum width, an apparently reliable age indicator in this species (Aznar et al. 1994). In the case of $P$. balaenopterae, the cephalothorax was extremely difficult to remove from the host's tissue 
(Abaunza et al. 2001), and exhibits a variable morphology depending on the site of attachment (Hogans 1987). We chose the total length of the external part of the body (i.e. abdomen + trunk + part of the neck) as a proxy of relative age. It should be noted that only a small portion of the body is buried in the blubber at a depth roughly proportional to the size of the parasite (Hogans 1987). Measurements were taken to the closest $0.01 \mathrm{~mm}$ with a digital gauge (Mitutoyo).

Estimation of reproductive status. Xenobalanus globicipitis is hermaphroditic and gravid individuals can be easily identified as they carry numerous eggs. Pennella balaenopterae is dioecious, but only inseminated females infect cetaceans; gravid females carry external thread-like ovisacs (Abaunza et al. 2001). Unfortunately, we had to establish reproductive status indirectly because the shell was the only structure available from many $X$. globicipitis individuals (see above) and ovisacs are often absent in specimens of Pennella spp. (see references in Hogan 1987). In the case of $X$. globicipitis, we randomly selected 62 whole specimens, measured shell diameter, and looked for the presence of eggs. A logistic regression indicated that shell diameter was a highly significant predictor of reproductive status (Wald statistic $=16.24,1 \mathrm{df}, \mathrm{p}<0.001) ; 83.9 \%$ of specimens were correctly classified as being gravid or nongravid. We adopted the value of shell diameter corresponding to $\mathrm{p}=0.5$ (>3.67 $\mathrm{mm})$ as a criterion to identify gravid individuals. This is obviously a rough criterion, but our aim was simply to compare samples under similar conditions. In the case of $P$. balaenopterae, we measured the external portion of the body in all specimens and looked for the presence of ovisacs. A logistic regression indicated that external body length was also a strong predictor of reproductive status (Wald statistic $=7.43,1 \mathrm{df}, \mathrm{p}=0.006$ ); $93.2 \%$ of individuals were correctly assigned to their group. Individuals with external body length > $93.3 \mathrm{~mm}$ (for $\mathrm{p}=0.5$ ) were considered gravid.

Statistical analyses. We followed the recommendations by Rósza et al. (2000) and Neuhäuser \& Poulin (2004) in describing infestations. Accordingly, for each sample we provided information on (1) prevalence (proportion of infected hosts); (2) mean intensity (mean no. of individuals per infected dolphin), with confidence intervals calculated according to the bias-corrected and accelerated bootstrap method (Rósza et al. 2000); (3) aggregation among dolphins, with 2 measures to characterize skewness, i.e. the variance to mean ratio and the exponent $k$ of the negative binomial distribution. Statistical comparisons were made with prevalence and intensity data.

Before performing comparisons, we explored the impact of 2 potentially confounding variables. The length (1-way ANOVA, p < 0.001) and the monthly distribution (Chi-Square test, exact $\mathrm{p}<0.0001$ ) of dolphins differed significantly among samples. However, the prevalence of the 2 crustacean species did not significantly change from June to December in any sample (exact $p$ in all Chi-Square tests $>0.10$ ), nor did the number of individuals per dolphin (Friedman tests for pre-E and Post-E, p > 0.40; Kruskal-Wallis test for E, $p>0.12)$. Neither did the latter variable correlate with dolphin length (nominal $\mathrm{p}$ for Spearman correlations for each period > 0.09). In summary, we considered that the effect of these confounding variables was negligible.

In the pre-E and Post-E samples, the data were arranged very sparsely in blocks, i.e. years. To test whether the prevalences of Xenobalanus globicipitis and Pennella balaenopterae were greater in the E sample we adopted 2 strategies. Firstly, we used 1-tailed Fisher's exact tests. Secondly, we examined whether the prevalence values observed in the E sample fell within the upper tail of the 95\% confidence interval (CI) of prevalences in the Pre-E and Post-E samples. CIs were set using 2 procedures: (1) for each sample, we calculated mean prevalence $\mathrm{yr}^{-1}$ and estimated the CI through 5000 bootstrap replications; (2) for each sample, we calculated the prevalence for the pooled sample of years and obtained bootstrap 95\% CIs by drawing among years. Both procedures rendered nearly identical results and therefore, the second option was chosen.

To compare intensity and age of infestation in the Pre-E and Post-E samples, we were able to use either data from individual dolphins (which maximized sample size but created a certain degree of non-independence because dolphins were nested in years), or averaged data per year (which alleviated non-independence but reduced sample size). All the tests described below were performed using both datasets and the results were similar. For brevity, we will present only the results using individual dolphins.

No single measure can capture all the differences of intensity between samples, thus we followed 2 procedures. The first procedure compared mean intensity between the $\mathrm{E}$ and the Pre-E samples and between the $\mathrm{E}$ and the Post-E samples with Welch's $t$-statistics based on 5000 bootstrap replications (Rósza et al. 2000). The second procedure used Brunner and Munzel's test (Neuhäuser \& Poulin 2004) which examines the probability that an individual host from one sample has a higher intensity value than an individual host from a second sample. Thus, the test considers the whole distribution of values rather than measures of central tendency (Neuhäuser \& Poulin 2004).

To explore whether infestations were relatively more recent in the E sample we used 2 procedures. Firstly, in 
each dolphin we selected the individuals of Xenobalanus globicipitis and Pennella balaenopterae with the maximum (MX) and minimum (MI) size, which were assumed to represent the oldest and most recent recruit, respectively, and the specimen with the median value (ME) in the infrapopulations as a measure of overall size distribution. We then used a 1-tailed MANOVA for each species, with MI, MX and ME as dependent variables. Comparisons were made between the $E$ and each of the other samples. In the case of Pennella balaenopterae we were only able to compare the E and the Post-E samples because we had no specimens from the Pre-E sample. Dependent variables were $\log _{10}$-transformed to achieve normality and homogeneous covariance matrices. In the second procedure we used 1-tailed Mann-Whitney tests to compare the proportion of reproductive individuals per dolphin between samples.

To examine the association between Xenobalanus globicipitis and Pennella balaenopterae we used 1-tailed Fisher's tests based on presence/absence data, and 1-tailed Spearman correlation tests based on the number of individuals per dolphin. In both analyses, double zeros were excluded to avoid spurious associations.

Statistical and terminological criteria. Ecological terminology follows Bush et al. (1997). In all tests, statistical significance was set at $p<0.05$, and power $=0.8$. Values of power will only be reported when low $(<0.7)$, and must be considered only as roughly indicative of the true power of the tests (Thomas 1997). In multiple comparisons, we also calculated p values corrected by the Sequential Bonferroni procedure (Rice 1989). The free software Quantitative Parasitology, v. 2.0, was used to calculate infestation parameters and perform Welch's $t$-tests (Rósza et al. 2000), StatXact v. 6.0 to calculate Monte Carlo and exact p values in contingency tables with sparse data, Power and Precision v.2.0 for most power analyses, and SSPS v. 11.0 for other statistical analyses. The power of MANOVA tests was calculated with SSPS based on the routine described by D'Amico et al. (2001), and the power of bootstrap comparisons with a routine described by R. Herrington for R (www. unt.edu/benchmarks/archives/2001/september01/rss.htm).

\section{RESULTS}

\section{Comparison of infestation parameters}

The distributions of Xenobalanus globicipitis and Pennella balaenopterae among dolphins in the Pre-E, E and Post-E samples are shown in Fig. 1. Two patterns can be observed. Firstly, the negative binomial distribution fitted the distribution of both species well in all samples $\left(\chi^{2}\right.$ test, all $\left.\mathrm{p}>>0.05\right)$, but both crustaceans tended to be less aggregated in the E sample. Secondly, the E sample was comparatively enriched with infected dolphins harbouring small numbers of individuals of both species, as indicated by the values of median intensity (Fig. 1).

Differences of prevalence among periods are shown in Fig. 2a. The prevalence of Xenobalanus globicipitis was higher in the E sample $(58.1 \%, \mathrm{n}=62)$ than in the
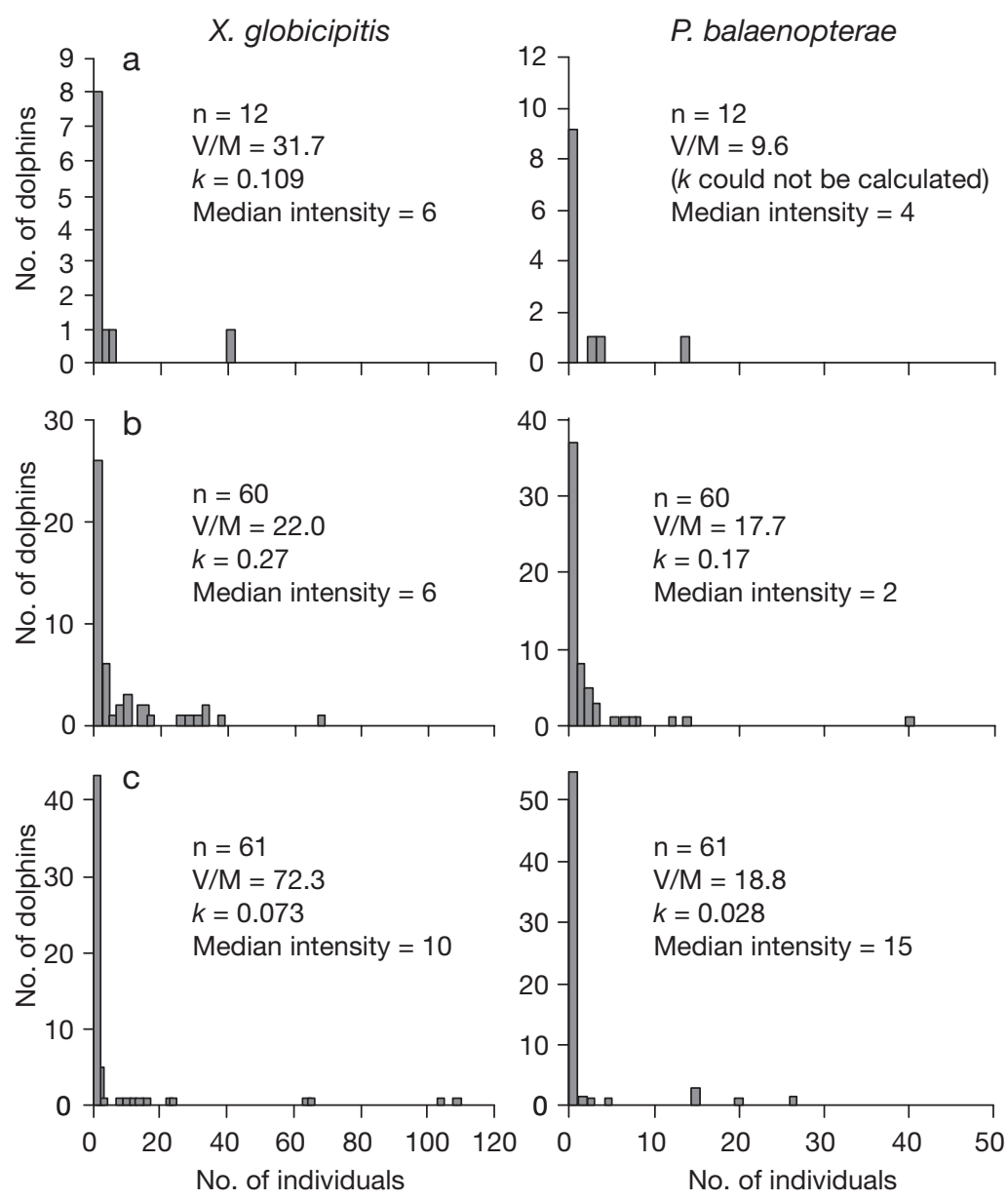

Fig. 1. Distribution of Xenobalanus globicipitis and Pennella balaenopterae in samples of striped dolphins Stenella coeruleoalba stranded along the Mediterranean coast of Spain. (a) Pre-epizootic period (June-December 19811989). (b) Epizootic period (June-December 1990). (c) Post-epizootic period (June-December 1991-2004). $\mathrm{n}=$ number of dolphins in each sample, $\mathrm{V} / \mathrm{M}=$ variance to mean ratio, $\mathrm{k}=$ parameter of the negative binomial distribution 

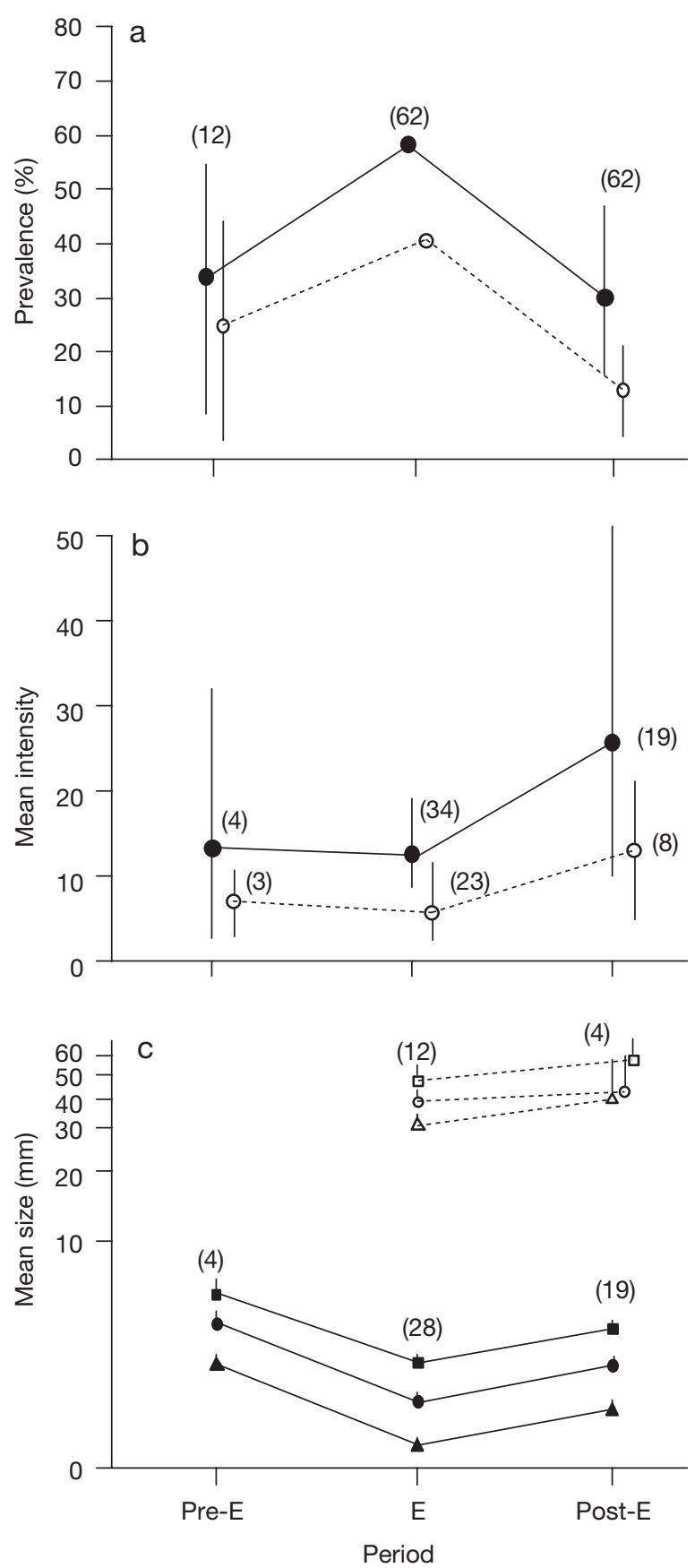

Fig. 2. Infestation changes of Xenobalanus globicipitis (solid symbols) and Pennella balaenopterae (open symbols) in striped dolphins Stenella coeruleoalba, during the preepizootic (pre-E), epizootic (E), and post-epizootic (Post-E) periods. Numbers in parentheses are the numbers of dolphins. (a) Prevalence. Vertical bars represent $95 \%$ confidence intervals based on 5000 bootstrap replications (see text for details). (b) Mean intensity. Bars represent 95\% confidence intervals based on 5000 bootstrap replications. (c) Mean size of maximum shell diameter ( $X$. globicipitis) and mean length of the external part of the body ( $P$. balaenopterae). Triangles, circles, squares $=$ specimens with the lowest, median, and highest values in the infrapopulations, respectively (see text for details). Bars represent standard error
Pre-E $(33.3 \%, \mathrm{n}=12)$ and Post-E samples $(30.6 \%, \mathrm{n}=$ $62) ;$ the observed value in the E sample was above the upper tail of the $95 \%$ CI of the other 2 samples (Fig. 2a). Fisher's test confirmed a highly significant difference with the Post-E sample (1-tailed $p=0.003$ ), but not with the Pre-E sample (1-tailed $p=0.104)$. The power associated with the latter test was low (0.48). The prevalence of Pennella balaenopterae was also higher in the E sample $(40.3 \%, \mathrm{n}=62)$ than in the PreE $(25.0 \%, \mathrm{n}=12)$ and the Post-E sample $(12.9 \%, \mathrm{n}=$ 62) (Fig. 2a). The observed value was above the upper $5 \%$ tail of the $95 \%$ CI of the Post-E sample, and above the upper $10 \%$ tail of the Pre-E sample (Fig. 2a). Fisher's test confirmed a highly significant difference between the $\mathrm{E}$ and the Post-E samples (1-tailed $\mathrm{p}=$ 0.001), but not between the $\mathrm{E}$ and the Pre-E samples (1-tailed $\mathrm{p}=0.25)$. Again, the power associated with the latter test was very low (0.14).

Mean intensities in the Pre-E, E, and Post-E samples are shown in Fig. 2b. Values were lower in the E sample, but we found no evidence of significant differences with the other samples: none of Welch's $t$-tests comparing mean intensities (all uncorrected 2-tailed $\mathrm{p}$ $>0.25$ ) or Brunner and Munzel's tests comparing the whole distribution of intensities (all uncorrected 2tailed $\mathrm{p}>0.17$ ) were significant. The power of tests ranged from 0.09 to 0.67 .

\section{Comparison of infestation age}

Shell diameter in Xenobalanus globicipitis ranged from 0.32 to $8.10 \mathrm{~mm}$ (mean $\pm \mathrm{SD}: 2.51 \pm 1.37$, median: $2.29, \mathrm{n}=844)$. The number of individuals did not differ significantly among the Pre-E, E, and Post-E samples (1-way ANOVA on the $\log _{10}$-transformed variable, $F_{(2,48)}=0.19$, 2-tailed $\left.\mathrm{p}=0.83\right)$. Mean values of MI, ME and MX shell diameter per sample are shown in Fig. 2c. Values were lowest in the E sample; the difference with the Pre-E sample was highly significant $\left(F_{(3,28)}=5.57,1\right.$ tailed $\mathrm{p}=0.002)$ and close to significance with the PostE sample $\left(F_{(3,43)}=1.84,1\right.$-tailed $\left.p=0.07\right)$. The power of these tests was low (maximum power observed $=0.51$ ). Interestingly, there was a significant relationship between the value of $\mathrm{MI}$ and infrapopulation size $\left(\mathrm{r}_{\mathrm{s}}=\right.$ $-0.60, \mathrm{n}=51, \mathrm{p}<0.001)$, suggesting that larger infrapopulations contained more recent recruits. If new recruits accumulated more recently during the epizootic, we would expect the slope of this relationship to be lowest in the E sample. This was the case (log-log relationship, $b=-0.45(\mathrm{E}) ; b=-0.15$ (Pre-E); $b=-0.32$ (Post-E) (Fig. 3). The difference of slopes was highly significant in the E vs. post-E samples $(t=3,99,43 \mathrm{df}, 1$ tailed $\mathrm{p}<0.001)$, and close to significance in $\mathrm{E}$ vs pre-E $(t=1.39,28 \mathrm{df}, 1$-tailed $\mathrm{p}=0.088)$. 


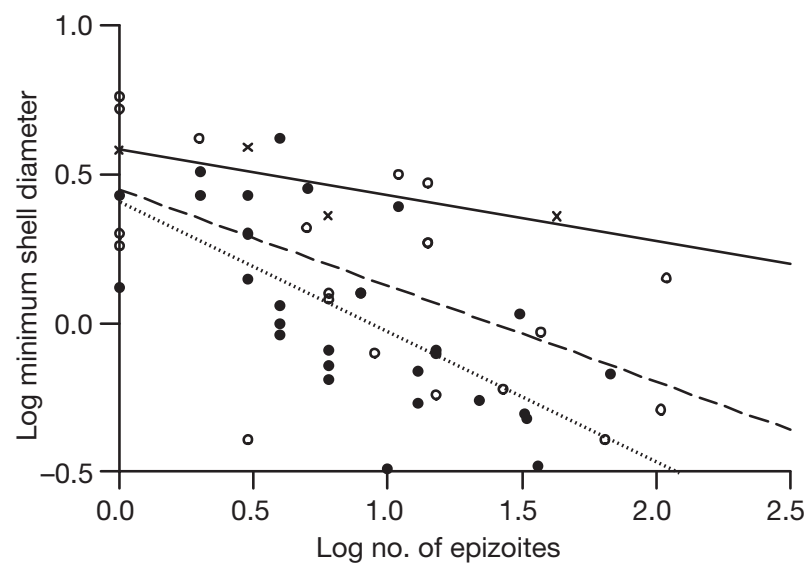

Fig. 3. Relationship between the number of Xenobalanus globicipitis per dolphin Stenella coeruleoalba and the size of the individual with the smallest shell diameter: $(x-x)$ preepizootic sample; $(\bullet . . . . \bullet)$ epizootic sample; (০---০) postepizootic sample

The length of the external body of Pennella balaenopterae ranged from 11.15 to $95.43 \mathrm{~mm}$ (mean \pm SD: $40.70 \pm 19.36$, median: $40.0, \mathrm{n}=73$ ). The number of individuals did not differ significantly among the $\mathrm{E}$ and Post-E samples ( $t$-test on the $\log _{10}$-transformed variable, $t=0.64,14 \mathrm{df}, 2$-tailed $\mathrm{p}=0.53$ ). Mean values of the MI, ME, and MX length of $P$. balaenopterae were significantly smaller in the E sample $\left(F_{(3,12)}=3.58,1\right.$ tailed $\mathrm{p}=0.024$ ) (Fig. 2c). The power associated to the MANOVA was low (0.38). We also found a significant negative relationship between the MI values and the number of $P$. balaenopterae individuals $\left(\mathrm{r}_{\mathrm{s}}=-0.41, \mathrm{n}=\right.$ 16, 1-tailed $\mathrm{p}=0.03$ ). A suitable linear regression model could only be achieved using ranked variables. The slope was more pronounced in the E sample $(b=$ -0.49) than in the Post-E sample $(b=-0.28)$, but the difference was not significant $(t=0.61,13 \mathrm{df}$, 1 -tailed $\mathrm{p}$ $=0.27)$. The power of the test was very low $(0.13)$.

The percentage of gravid individuals of Xenobalanus globicipitis per dolphin is shown in Fig. 4. In the E sample, the proportion of gravid individuals per infrapopulation was low (mean \% \pm SD: $8.4 \pm 22.6$, median: 0.0, $\mathrm{n}=28$ ) compared with that of the Pre-E sample $(75.2 \pm 31.9$, median: $83.7, \mathrm{n}=4)$ and the PostE sample $(38.3 \pm 40.2$, median: $22.6, \mathrm{n}=19)$ which harboured comparatively more gravid individuals. This was confirmed statistically (E vs. Pre-E: $U=5.5$, exact 1-tailed $\mathrm{p}=0.001$; E vs Post-E: $U=143.5, \mathrm{p}=$ 0.001). Only 4 individuals of Pennella balaenopterae ( 2 from the E samples and 2 from the Post-E sample) were observed to carry ovisacs. When the morphometrical criterion was applied to determine reproductive status, only 3 individuals were considered as gravid and, therefore, no statistical tests were performed for $P$. balaenopterae.

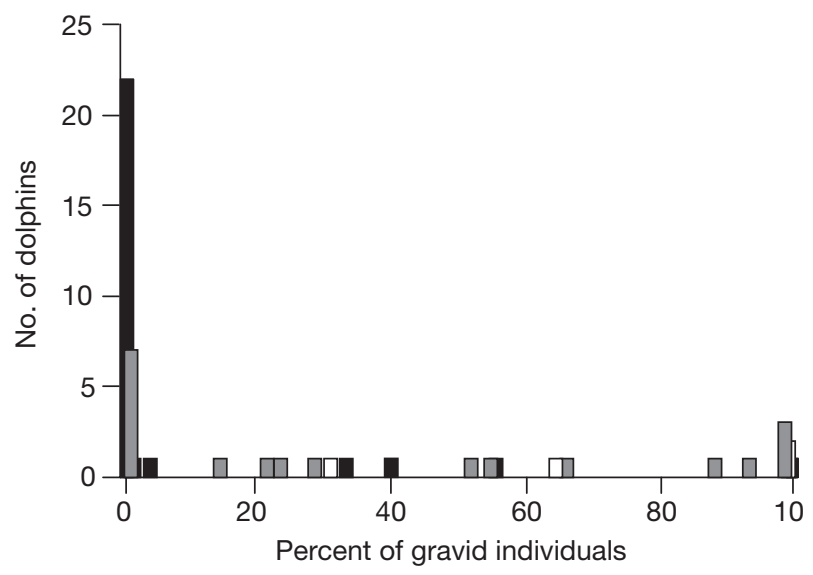

Fig. 4. Distribution of infrapopulations of Xenobalanus globicipitis among striped dolphins Stenella coeruleoalba according to the percentage of gravid individuals: open bars = pre-epizootic sample; black bars = epizootic sample; grey bars $=$ post-epizootic sample

\section{Association between Xenobalanus globicipitis and Pennella balaenopterae}

In the E sample, Fisher's test showed a significant positive association between Xenobalanus globicipitis and Penella balaenopterae $(\mathrm{p}=0.03)$. However, the association was not significant either in the Pre-E sample $(p=0.60)$ or in the Post-E sample $(p=0.38)$. The covariation in the numbers of both species was negative and not significant in any sample (all uncorrected 2 -tailed $\mathrm{p}>0.08$ ). With the exception of the tests involving the E sample, the power of tests was $<0.28$.

\section{DISCUSSION}

We faced some sampling problems when comparing infestations of Xenobalanus globicipitis and Pennella balaenopterae before, during and after the epizootic since for a number of years only sparse were data available for the pre-E and Post-E samples. This certainly added variability to the variables to be compared (see Fig. 2), but is unlikely to have confounded the results because we controlled for seasonal effects, and we found negligible effects of other influential variables. A potentially more serious problem is that the effect of the epizootic itself could have influenced infestation parameters in dolphins from the Post-E sample. However, our analyses indicate that only the prevalence of $X$. globicipitis was affected (F. J. Aznar unpubl. data). In addition, the pattern of change in all variables examined was very consistent before and after the epizootic, and is ecologically significant (see below). Finally, changes were fully congruent in 2 species with unrelated life styles. The life cycle of $X$. globicipitis is direct 
and involves free-swimming cyprid larvae that infest dolphins (see Zardus \& Hadfield 2004). In contrast, $P$. balaenopterae is parasitic and has an indirect cycle: hatched nauplii become copepodids that use fish or molluscs to become adult and mate; free-swimming inseminated females have to attach to a cetacean host to produce the offspring (Kabata 1979, Arroyo et al. 2002).

Another problem was that host sample sizes were small, particularly in the pre-E sample. Thus, some patterns could be ecologically significant, yet statistically undetectable because of a lack of power. We used 2 criteria to assist interpretation of non-significant results, i.e. the comparison of size effects in tests with different sample sizes, and the congruence of patterns between Xenobalanus globicipitis and Pennella balaenopterae. We assumed that if patterns of both species were consistent and allowed a coherent ecological interpretation, the reliance on statistical criteria alone might be misleading. According to these criteria, the following patterns were considered to be ecologically significant: (1) the prevalence of both X. globicipitis and $P$. balaenopterae increased during the epizootic; (2) their intensity of infestation did not increase; indeed, it was even slightly lower than in the other periods, as was the degree of aggregation among dolphins; (3) overall, individuals of both species were more recently recruited and (4) the 2 species tended to co-occur in the same dolphins, although their numbers did not co-vary. These patterns strongly suggest that the CeMV disease increased host susceptibility, thus enhancing opportunities for infestation by $X$. globicipitis and $P$. balaenopterae. In the following we discuss this hypothesis in more detail.

Our hypothesis assumes that the E sample contained more dolphins susceptible to infestations with epizoic crustaceans. Indeed, the dolphins affected by the CeMV suffered from severe immunosuppression, probably as a direct effect of the virus (Domingo et al. 1992). Sick dolphins also showed abnormally high levels of polychlorinated biphenyls (PCBs) compared with individuals sampled before and after the epizootic, and PCBs also induce immunosuppression (Aguilar \& Borrell 1994). Moreover, sick dolphins exhibited an elevated level of inbreeding with respect to dolphins stranded after the epizootic, and inbreeding is related to propensity to infectious diseases and parasitic infections (Valsecchi et al. 2004). Regardless of how these factors interacted (see Aguilar \& Borrell 1994, Valsecchi et al. 2004), it seems clear that sick dolphins were particularly susceptible to opportunistic infections with a variety of organisms (Domingo et al. 1992). We do not know the exact mechanism that might have increased susceptibility to infestations with Xenobalanus globicipitis and Pennella balaenopterae, but it could be related to the general impairment of the immune sys- tem, and/or the reduction of the regenerative and immune functions of the skin (Aznar et al. 1994; see Meyer \& Seegers 2003 for immune mechanisms). In addition, sick dolphins could have suffered from behavioural alterations that perhaps facilitated infestations, such as reduced swimming speed (Aznar et al. 1994). In any event, our hypothesis also requires that the Pre-E and Post-E samples contain a lower proportion of susceptible hosts. This seems reasonable because there was not a common cause of death for all individuals. Many dolphins (a minimum 20\% of the total sample) likely died because of direct interaction with humans (from injuries or entanglement in fishing gear). Also, based on evidence from other studies (see e.g. Baker 1992, Baker \& Martin 1992), other dolphins probably died from natural causes that implied lower or no necessary alterations of susceptibility to infestations with $X$. globicipitis and $P$. balaenopterae. Finally, some dolphins might have died from debilitating diseases, and were, perhaps, the animals most heavily infected with both crustacean species.

Our hypothesis is strongly supported by the change of infestation parameters during the epizootic. Interestingly, the prevalence of both Xenobalanus globicipitis and Pennella balaenopterae in the overall 'non-epizootic' sample (38.7\% and $9.4 \%$, respectively) is strikingly similar to that found in striped dolphins from other Mediterranean localities under 'normal' conditions (Pilleri 1970, Cerioni \& Mariniello 1996, Cornaglia et al. 2000). During the epizootic, prevalences rose but, contrary to our initial expectation, intensities did not. This contrasting result can be accounted for by epidemiological models developed for marine ectoparasites (Murray 2002). If the number of susceptible hosts increases in the population, we can predict an increase in the proportion of infected hosts. However, if we focus on the group of infected dolphins in a sample of stranded animals, the number of recruits in each host will be more dependent on the individual history of contacts with infective stages. We find no reason to believe that the infected hosts in the E sample were exposed to more infective stages than the infected (susceptible) hosts from the other samples, particularly if the spatial distribution of infective stages is patchy (Murray 2002). It is even possible that the dolphins affected by the CeMV disease died before they could become host to many individuals of $X$. globicipitis and $P$. balaenopterae. This could help explain why mean intensities of both species were slightly lower in the E sample (see intensity distributions in Fig. 1b).

If the population of susceptible hosts suddenly increased during the epizootic, we would also predict new recruitment of both Xenobalanus globicipitis and Pennella balaenopterae, in part to hosts not previously infected. However, the early death of the dolphins 
should limit the growth of the new recruits. Our analysis confirms this nicely. Firstly, the E sample was enriched with comparatively smaller individuals of $X$. globicipitis and P. balaenopterae. Secondly, the regressions of the number of individuals against the size of the smallest individual suggests that recruitment might have continued until immediate death in dolphins from the E sample. Thirdly, many more infrapopulations of $X$. globicipitis from the E sample lacked gravid individuals. This makes sense as the time for $X$. globicipitis to reach sexual maturity (from 60 to $90 \mathrm{~d}$, see Arvy 1982), is longer than the interval between CeMV infection and death (about $40 \mathrm{~d}$, see Aznar et al. 1994). In this context, we were surprised to find so few gravid specimens of $P$. balaenopterae. Perhaps the striped dolphin is not a suitable host for this species. According to the literature, P. balaenopterae occurs typically in large cetaceans (Hogans 1987), in which it usually reaches over $200 \mathrm{~mm}$ (Abaunza et al. 2001, and references therein). The most complete morphological study in the Mediterranean dealt with 4 cetacean species and included 2 large species, the fin whale Balaenoptera physalus and Cuvier's beaked whale Ziphius cavirostris (Brzica 2004). The length of the exposed part of the body ranged from 104 to $150 \mathrm{~mm}$ ( $\mathrm{n}=17$ ), above the maximum value recorded in our sample $(95 \mathrm{~mm})$.

The hypothesis of an increased susceptibility is confirmed by the significant association between Xenobalanus globicipitis and Pennella balaenopterae in the E sample. Since each species has a different life-style and site selection in the dolphins, their co-occurrence could arguably be explained by the increase of host proclivity to infestation (Holmstad \& Skorping 1998). Our data showed no significant covariation in numbers but, as argued above, infrapopulation sizes would be more dependent on the idiosyncratic history of infestations in each dolphin.

The 'host susceptibility' hypothesis cannot rule out that the likelihood of contact between dolphins and the infective stage of Xenobalanus globicipitis and Pennella balaenopterae also increased during the epizootic period: perhaps the density of infective stages was especially high during the summer and fall of 1990 and/or dolphins spent more time in patches where infective stages were more abundant. Whether this happened is highly speculative, but it is interesting to note that the epizootic was preceded by a period of abnormally high temperatures (Aguilar \& Raga 1993) and this abnormal weather perhaps altered the population dynamics of both $X$. globicipitis and P. balaenopterae or the movement patterns of dolphins (Kennedy 1998). In any event, this argument alone seems insufficient to explain the coincidental changes of infestation in 2 species with different life-styles, the significant association between both species, or the post-epizootic patterns.

In conclusion, this study provides now convincing evidence that, during the epizootic of Mediterranean striped dolphins, there was a short-term increase in the probability of infestation of some epizoic crustaceans which could be attributed to the sudden rise of the population of susceptible hosts. The CeMV could be the main, but probably not the only, agent involved. It is worth noting that there were previous records of other dolphin species affected by morbilliviruses that also appeared to have increased burdens of barnacles (Brody 1989). As a more general conclusion, the relevance of phoronts and directly transmitted ectoparasites as indicators of debilitating pathologies in small cetaceans should not be overestimated. The observation of heavy infestation loads in wild cetacean populations, or long-term increasing trends of infestations in stranded animals, could be signals of poor health among these cetacean populations.

Acknowledgements. This study was made possible thanks to the invaluable assistance of the Conselleria de Territori i Habitatge, Generalitat Valenciana, Spain. We thank all the members of our stranding network for their invaluable assistance with stranded animals, and J.A. Balbuena and M. Fernández for comments on an earlier draft of this manuscript. This study was supported by Project GV2004-B-304 of the Conselleria de Cultura i Educació, Generalitat Valenciana, Spain. The senior author benefits from a 'Ramón y Cajal' contract from the Ministerio de Educación y Ciencia (MEC) of Spain.

\section{LITERATURE CITED}

Abaunza P, Arroyo NL, Preciado I (2001) A contribution to the knowledge on the morphometry and the anatomical characters of Pennella balaenopterae (Copepoda, Siphonostomatoida, Pennellidae), with special reference to the buccal complex. Crustaceana 74:193-210

Aguilar A, Raga JA (1993) The striped dolphin epizootic in the Mediterranean Sea. Ambio 22:524-528

Aguilar A, Borrell A (1994) Abnormally high polychlorinated biphenyl levels in striped dolphins (Stenella coeruleoalba) affected by the 1990-1992 Mediterranean epizootic. Sci Total Environ 154:237-247

Arroyo NL, Abaunza P, Preciado I (2002) The first naupliar stage of Pennella balaenopterae Koren and Danielssen, 1877 (Copepoda: Siphonostomatoida, Pennellidae). Sarsia 87:333-337

Arvy L (1982) Phoresis and parasitism in cetaceans: a review. Investig Cetacea 14:233-335

Aznar FJ, Balbuena JA, Raga, JA (1994) Are epizoites biological indicators of a western Mediterranean striped dolphin die-off? Dis Aquat Org 18:159-163

Baker JR (1992) Causes of mortality and parasites and incidental lesions in dolphins and whales from British waters. Vet Rec 130:569-572

Baker JR, Martin AR (1992) Causes of mortality and parasites and incidental lesions in harbour porpoises (Phocoena phocoena) from British waters. Vet Rec 130:554-558. 
Brody M (1989) Explaining sea mammal deaths proves challenging. Am Soc Microbiol News 55:595-598

Brzica H (2004) Morphological and morphometric characteristics of the ectoparasite Pennella balaenopterae (Copepoda, Siphonostomatida, Pennellidae) of whales (Cetacea) from the Adriatic Sea. MSc Thesis, University of Zagreb, (in Serbo-Croatian)

Bush AO, Lafferty KD, Lotz JM, Shostak AW (1997) Parasitology meets ecology on its own terms: Margolis et al. revisited. J Parasitol 83:575-583

Cerioni S, Mariniello L (1996) Metazoi parassiti di Stenella coeruleoalba (Cetacea: Delphinidae) spiaggiata lungo le coste laziali dal 1985 al 1991. Parassitologia 38:505-510

Cornaglia E, Rebora L, Gili C, DiGuardo G. (2000) Histopathological and immunohistochemical studies on cetaceans found stranded on the coast of Italy between 1990 and 1997. J Vet Med Ser A 47:129-142

D'Amico EJ, Neilands TB, Zambarano R (2001) Power analysis for multivariate and repeated measures designs: a flexible approach using the SPSS MANOVA procedure. Behav Res Methods Instrum Comput 33:479-84

Di Guardo G, Marruchella G, Agrimi U, Kennedy S (2005) Morbillivirus infections in aquatic mammals: a brief overview. J Vet Med Ser A 52:88-93

Domingo M, Visa J, Pumarola M, Marco AJ, Rabanal R, Kennedy S (1992) Pathologic and immunocytochemical studies of Morbillivirus infection in striped dolphins (Stenella coeruleoalba). Vet Pathol 29:1-10

Duignan PJ, House C, Odell DK, Wells RS and 5 others (1996). Morbillivirus infection in bottlenose dolphins: evidence for recurrent epizootics in the western Atlantic and Gulf of Mexico. Mar Mamm Sci 12:499-515

Forcada J, Aguilar A, Hammond P, Pastor X, Aguilar R (1994) Distribution and numbers of striped dolphins in the western Mediterranean Sea after the 1990 epizootic outbreak. Mar Mamm Sci 10:137-150

Hogans WE (1987) Morphological variation in Pennella balaenoptera and P. filosa (Copepoda: Pennellidae) with a review of the genus Pennella Oken, 1816 parasitic on Cetacea. Bull Mar Sci 40:442-453

Holmstad P, Skorping A (1998) Covariation of parasite intensities in willow ptarmigan, Lagopus lagopus L. Can J Zool

Editorial responsibility: Murray Dailey,

Sausalito, California, USA
$76: 1581-1588$

Kabata, Z (1979) Parasitic Copepoda of British fishes, Vol 152. The Ray Society, London

Kennedy S (1998) Morbillivirus infections in aquatic mammals. J Comp Pathol 119:201-225

López A, Santos MB, Pierce GJ, González AF, Valeiras X, Guerra A (2002) Trends in strandings and by-catch of marine mammals in north-west Spain during the 1990s. J Mar Biol Assoc UK 82:513-521

Meyer W, Seegers U (2003) A preliminary approach to epidermal antimicrobial defense in the Delphinidae. Mar Biol 144:841-844

Murray AG (2002) Using observed load distributions with a simple model to analyse the epidemiology of sea lice (Lepeophtheirus salmonis) on sea trout (Salmo trutta). Pest Manag Sci 58:585-594

Neuhäuser M, Poulin R (2004) Comparing parasite numbers between samples of hosts. J Parasitol 90:689-691

Pilleri G (1970) Xenobalanus globicipitis Steenstruup on Delphinus delphis, Stenella styx and Tursiops truncatus of the western Mediterranean. Investig Cetacea 2:248-249

Rice WR (1989) Analyzing tables of statistical tests. Evolution 43:223-225

Rózsa L, Reiczigel J, Majoros G (2000) Quantifying parasites in samples of hosts. J Parasitol 86:228-232

Thomas, L (1997) Retrospective power analysis. Conserv Biol 11:276-280

Valsecchi E, Amos W, Raga, JA, Podesta M, Sherwin W (2004) The effects of inbreeding on mortality during a morbillivirus outbreak in the Mediterranean striped dolphin (Stenella coeruleoalba). Animal Cons 7:139-146

Van Bressem MF, Van Waerebeek K, Raga JA (1999) A review of virus infections of cetaceans and the potential impact of morbilliviruses, poxviruses and papillomaviruses on host population dynamics. Dis Aquat Org 38: 53-65

von Messling V, Springfeld C, Devaux P, Cattaneo R (2003) A ferret model of canine distemper virus virulence and immunosuppression. J Virol 77:12579-12591

Zardus JD, Hadfield MG (2004) Larval development and complemental males in Chelonibia testudinaria, a barnacle commensal with sea turtles. J Crustac Biol 24:409-21

Submitted: May 16, 2005; Accepted: August 24, 2005

Proofs received from author(s): November 2, 2005 